\title{
IGUALDAD, GENERALIDAD, RAZONABILIDAD Y CRISIS DE LA LEY
}

\author{
Liborio L. Hierro \\ Universidad Autónoma de Madrid
}

\section{Introducción}

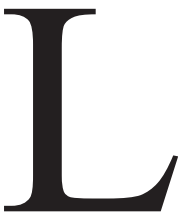

a reunión para la cual escribí este trabajo fue convocada bajo el título "Igualdad, crisis de la ley, razonabilidad". ${ }^{1}$ Puesto que la igualdad se vincula con frecuencia a la generalidad de las leyes y la crisis de la ley se vincula en parte, también con frecuencia, a su supuesta pérdida de generalidad, me parece oportuno, si no necesario, añadir a los términos de la convocatoria el de "generalidad", por lo que este trabajo se titula "Igualdad, generalidad, razonabilidad y crisis de la ley” y ello a pesar de que mis argumentos vendrán a confirmar algo que, probablemente, el título de la convocatoria estaba insinuando. Dedicaré una primera sección a plantear el problema y una sección sucesiva a cada uno de estos cuatro ítems. Resultará claro, espero, que de los cuatro el que a mí más me interesa es el de la igualdad. La igualdad entre los seres humanos me parece que es un valor moral, un ideal social, un principio político y, además, un derecho de las personas. La generalidad, por el contrario, no me parece muy interesante y creo que tiene poco que ver con la igualdad. Es más, es fácil demostrar que la igualdad requiere normasmenos-que-generales o, mejor dicho, normas desigualitarias. Es cierto, sin embargo, que cuando se asume como punto de partida la igualdad entre los seres humanos cada norma desigualitaria requiere una específica justificación que hoy suele subsumirse bajo la elusiva idea de la "razonabilidad". De

${ }^{1}$ Este trabajo fue preparado para la última sesión del IX Seminario hispano-italiano de Teoría del Derecho que se celebró los días 10 y 11 de Octubre de 2003 en Agrigento. Forma parte del Proyecto de Investigación "Los derechos entre la teoría jurídica y la filosofía politica” del Plan Nacional de Investigación Científica, Desarrollo e Innovación Tecnológica, financiado por el Ministerio de Ciencia y Tecnología (Proyecto $\mathrm{n}^{\circ}$ BJU 2002-00467). Agradezco a Alfonso Ruiz Miguel sus observaciones críticas que me obligaron a introducir correcciones importantes y a matizar sensiblemente mis apreciaciones sobre la irrelevancia de la generalidad y la abstracción. 
la crisis de la ley me ocupé hace algunos años y no he cambiado de opinión cuando, en estos últimos meses, he leído dos sesudas y muy bien construidas tesis doctorales sobre el tema; ${ }^{2}$ no creo en la crisis de la ley o creo que la ley siempre ha estado en crisis, lo que para el caso es lo mismo. Las mencionadas tesis doctorales me han confirmado en ello; sus respectivos autora y autor sostienen, con abundante apoyo bibliográfico, que la ley siempre ha estado en crisis; si esto es cierto resulta difícil encontrar algo nuevo en lo que hoy se ha puesto de moda como "crisis de la ley" y, si es que hay algo nuevo, me parece que tiene poco que ver con la igualdad.

Recurriré a algunos cuentos. Quien haya leído el libro de Peter Westen, que es el mejor análisis del concepto de igualdad que conozco, verá enseguida que lo de recurrir a cuentos probablemente me ha sido inspirado por él. Respecto al centro de la cuestión, la igualdad política y las leyes, creo que una gran parte de lo que pienso proviene del excelente trabajo de Francisco Laporta de 1985 y de los numerosos trabajos sobre la igualdad de Alfonso Ruiz Miguel (básicamente: 1994, 1995, 2002a y 2002b) .

\section{Planteamiento del problema}

Creo que es un tópico generalmente admitido en el pensamiento político y jurídico contemporáneo que "dado que el principio de igualdad no excluye las desigualdades, antes al contrario las admite siempre que tengan una justificación objetiva y razonable, el control de constitucionalidad de la desigualdad legislativa es, en el fondo, un control de su razonabilidad" (Martínez Tapia 2000, p. 11). Sin embargo cualquier matemático, o incluso cualquier persona normal y corriente ajena a las disquisiciones político-jurídicas, consideraría un oximoron afirmar que la igualdad no excluye las desigualdades sino que las admite. La afirmación de que $10=4+6$ no admite ninguna desigualdad. La afirmación de que las personas negras son iguales a las personas blancas no admite ninguna desigualdad.

El objeto de este artículo es, en primer lugar, analizar la relación entre la igualdad de los seres humanos y la generalidad y abstracción de las normas jurídicas. La igualdad de los seres humanos puede enunciarse como

\footnotetext{
${ }^{2}$ La primera, Crisis de la ley y Ciencia de la legislación, es obra de Gema Ma Marcilla Córdoba bajo la dirección de Marina Gascón. Se leyó el pasado mes de Junio en la Facultad de Derecho de la Universidad de Castilla La Mancha (Albacete) y recibió con todo merecimiento la máxima calificación. La segunda, Crisis de la ley y Estado Constitucional, es obra del mejicano Miguel Angel Suárez Romero bajo la dirección de Francisco J. Ansuátegui y se encuentra ya depositada, y sólo pendiente de lectura, en la Universidad Carlos III. El trabajo mío al que me refiero, El imperio de la ley y la crisis de la ley, se publicó primero en DOXA nº 19 (1996), pp. 287-308, y luego como primer capítulo del libro Estado de Derecho. Problemas actuales, 1998, Editorial Fontamara, México, (segunda edición 2001).
} 
un valor o como un derecho. ${ }^{3}$ Su afirmación como un valor no implica que constituya un derecho, pero su afirmación como un derecho sí implica que constituye un valor. Sea que se afirme sólo como un valor sea que se afirme como un derecho, la realización normativa de la igualdad pareció exigir que las normas fueran generales y abstractas. ${ }^{4}$ Las normas singulares o concre-

\footnotetext{
${ }^{3}$ Kai Nielsen distingue entre la igualdad "as a goal" y la igualdad "as a right” y señala que "what starts as a goal-what in some historical circunstances is little more than a heuristic ideal- turns into a right when the goal can realistically be achieved" (Nielsen 1985, p. 9). Suscribo su criterio de cómo un objetivo ideal puede convertirse en un derecho (Hierro 1982, pp. 59-60, aunque mi tesis es que, además, los derechos se vinculan a necesidades). Muchas constituciones contemporáneas, y entre ellas la Constitución Española, permiten distinguir entre valores, principios y derechos; en este sentido es lo más frecuente decir, por ejemplo, que en la Constitución Española la igualdad se enuncia como un valor en el artículo 1.1, como un principio en los artículos 9.2 y 14 y como un derecho sólo en el artículo 14. En todo caso este tipo de enunciados proporciona a los valores o principios (o "goals") un fuerte sesgo jurídico-normativo.

${ }^{4}$ El lugar clásico es la afirmación de Rousseau: "Cuando digo que el objeto de las leyes es siempre general, entiendo que la ley considera a los súbditos en cuanto cuerpos y a las acciones como abstractos: nunca toma a un hombre como individuo ni una acción particular..." (Rousseau [1762] 1969, p. 50). Más adelante discutiré esta afirmación de Rousseau. Como es sabido, Norberto Bobbio señaló, de un lado, que la generalidad y abstracción no son requisitos "de la norma jurídica como es, sino como debería ser, para corresponder al ideal de justicia ... estos son requisitos no tanto de la norma jurídica (o sea, de la norma válida en determinado sistema), sino de la norma justa" y, de otro lado, que el valor que inspira la generalidad es el de la igualdad y el valor que inspira la abstracción es el de la certeza (Bobbio 1991, pp. 144-145). Esto, como veremos, parece más que discutible.
}

No quiero entretenerme ahora en cuestiones terminológicas, aunque puedan tener implicaciones conceptuales importantes, sobre "generalidad "y "abstracción”. Von Wright llamó prescripción particular a la que tiene por sujeto un individuo humano específico y prescricpión general a la que tiene por sujeto a todos los hombres o a todos los hombres que respondan a una cierta descripción (Von Wright 1979, p. 94). Esto es muy llamativo porque, con relación a la ocasión, Von Wright parece cambiar el criterio al llamar particular tanto a la prescripción que se refiere a una ocasión específica como a la que se refiere a un número finito de ocasiones específicas y general a la que se refiere a un número ilimitado de ocasiones (ibídem, pp. 95-96). Ross, por su parte, distinguió entre normas individuales, genéricas y universales, según el sujeto esté especificado como clase cerrada, como clase abierta o incluya a todo el mundo y aplica el mismo criterio a la ocasión (Ross 1971, pp. 104-106). Bobbio llama normas universales o generales a las que tienen como sujeto a una clase de personas y normas particulares a las que tienen como sujeto a un individuo concreto, normas abstractas a las que regulan una accióntipo y normas concretas a las que regulan una acción particular (Bobbio 1991, pp. 142-144). Yo utilizaré aquí la terminología tradicional de generales-particulares y abstractas-concretas entendiendo por generales las que tienen como sujeto a conjuntos amplios de personas (aunque sean conjuntos cerrados) y por particulares a las que tienen como sujeto a una persona o un conjunto pequeño de personas (aunque sean conjuntos abiertos). Las normas serían absolutamente generales si se refieren a todas las personas y absolutamente individuales si se refieren a un individuo concreto. A los efectos de este trabajo me parece mejor este criterio, quizás poco ortodoxo, pero trato de no considerar general a una norma que, por ejemplo, se refiera a un conjunto abierto pero muy pequeño como serían normas cuyo sujeto fuera "el heredero de la Corona" o "los Fiscales de Sala del Tribunal Supremo". No pretendo, con ello, impugnar 
tas parecían infringir el valor de la igualdad o el derecho a la igualdad al introducir diferentes tratamientos normativos entre unos seres humanos y otros ya fuera en atención a características específicas de ciertos sujetos o grupos de sujetos (normas singulares) o a características de ciertas ocasiones o tipos de ocasiones en que los sujetos se encuentren (normas concretas). En consecuencia, la igualdad de los seres humanos parecería exigir que todas las normas que tienen como destinatario (sujeto) a un ser humano fueran generales y abstractas; es decir: estuvieran dirigidas a todos los seres humanos en cualesquiera circunstancias.

"Todos tienen derecho a la vida y a la integridad fisica y moral", tal y como establece el artículo 15 de la Constitución Española, sería un ejemplo cabal de norma general y abstracta. Esta norma trata, en efecto, a todos por igual.

Una norma puede ser menos general (o más singular) y abstracta.

"Los españoles son iguales ante la ley", tal y como establece el artículo 14 de la Constitución Española, es una norma menos general (o más singular) pero abstracta. Esta norma no trata igual a los españoles y a los no-españoles (extranjeros).

Una norma puede ser menos abstracta (o más concreta) y general.

"El que matare a otro será castigado, como reo de homicidio, con la pena de prisión de diez a quince años", tal y como establece el artículo 138 del Código Penal español actualmente vigente, es una norma general pero menos abstracta (o más concreta). Esta norma no trata igual a los que han matado a otro y a los que no han matado a otro.

Una norma puede ser menos general (o más singular) y menos abstracta (o más concreta).

"La Corona de España es hereditaria en los sucesores de S.M. Don Juan Carlos I de Borbón, legítimo heredero de la dinastía histórica", tal y como establece el artículo 57 de la Constitución Española, es una norma bastante singular y bastante concreta. Esta norma no trata igual a los sucesores de Don Juan Carlos y a los que no son sus sucesores, pero sólo los distingue respecto a la posibilidad de heredar la corona.

Sin duda lo que quieren decir quienes afirman que la igualdad no excluye las desigualdades es que el principio de que todos los seres humanos valen igual, o la afirmación de que todos los seres humanos tienen derecho a ser tratados como iguales, no implica que todos los seres humanos deban ser tratados del mismo modo (igualmente) en cualquier ocasión, o que tengan derecho a ser tratados del mismo modo (igualmente) en cualquier ocasión. ${ }^{5}$

la corrección de la distinción lógica sino señalar que tal distinción lógica es poco relevante a los efectos político-jurídicos de saber si una norma que establece un determinado tratamiento lo establece para muchos o para pocos. Por supuesto ello es independiente, a su vez, de que el tratamiento diferencial esté o no esté justificado. 
En efecto, si asumiésemos como premisa mayor que la justicia como igualdad se reduce a "tratar igualmente lo que es igual" y como premisa menor que "todos los hombres son iguales", la conclusión sería que todos los hombres deben ser tratados del mismo modo (igualmente) con total independencia de cualquier característica específica u ocasión específica. El único tipo de norma justa sería el del primer ejemplo. La norma del segundo ejemplo debería decir "Todos son iguales ante la ley", lo que a muchos les resultaría efectivamente más justo que lo que establece la norma del ejemplo. ${ }^{6}$ La norma del tercer ejemplo debería decir "Todos serán condenados a la pena de prisión de diez a quince años", lo que, sin embargo, a cualquiera le resultaría tan injusto como absurdo; por no decir nada del cuarto ejemplo que requeriría algo así como "La Corona de España es hereditaria en todos".

Ello quiere decir que el principio de igualdad entre todos los seres humanos no implica que todos los seres humanos deban ser tratados (o tengan derecho a ser tratados) del mismo modo en cualquier ocasión. El corolario es que el principio de igualdad entre todos los seres humanos es, en cuanto principio de justicia, un principio relativo al sujeto pero no un principio relativo a la ocasión y, por ello, que el problema de la igualdad se convierte en el problema de la desigualdad: ${ }^{7}$ ¿cuándo y cómo está justificado tratar de diferente modo a los seres humanos? Sean cuales sean los casos en que esté justificado tratar de diferente modo a los seres humanos, las normas que lo hagan serán normas menos-que-absolutamente-generales o menos-que-absolutamente-abstractas.

\section{Sobre la igualdad y cómo el derecho a la igualdad requiere un Derecho desigual}

Laporta ha señalado que "la idea de igualdad pasa por ser uno de los parámetros fundamentales del pensamiento social, jurídico y político de nuestro tiempo" (Laporta 1985, p. 3) y Will Kymlicka dedicó su conocido libro de 1990 a "examinar una sugerencia, presentada por Ronald Dworkin, según la cual las teorías políticas modernas no tienen valores fundacionales diferentes. De acuerdo con la postura de Dworkin, -señala Kymlicka-cada teoría política plausible tiene el mismo valor último, que es la igualdad"

\footnotetext{
${ }^{5}$ Ha sido Dworkin quien, con particular influencia, ha distinguido entre el derecho a un trato igual y el derecho a ser tratados como iguales para afirmar que "el derecho a ser tratado como igual es fundamental, y el derecho a igual tratamiento, derivado” (Dworkin 1984, p. 332).

${ }^{6}$ He discutido particularmente este punto en relación con las tesis de Javier de Lucas y Manuel Atienza en Hierro 1995, passim.

${ }^{7}$ Vid. Laporta 1985, pp. 15 y 17, y Martínez Tapia 2000, p. 19.
} 
(Kymlicka 1995, p. 14). Puesto que la obra de Kymlicka es una obra de "filosofía política normativa" o "teoría de la justicia" (ibídem pp. 11 y 17) el planteamiento no debería resultar muy novedoso ya que desde Aristóteles venimos entendiendo que la justicia es una cuestión de igualdad.

"Por ejemplo, parece que la justicia consiste en igualdad, y así es, pero no para todos, sino para los iguales, y la desigualdad parece ser justa, y lo es en efecto, pero no para todos, sino para los desiguales" (Aristóteles, Política, III, 9,1280 a, 11-14)

Lo que, en realidad, nos separa radicalmente de Aristóteles y de los siglos posteriores hasta finales del XVIIIl no es la configuración de la justicia como igualdad, sino la asunción de que todos los hombres son iguales. Dicho en términos de Bobbio, lo que hoy parece resuelto por unaniminidad es la primera pregunta sobre la igualdad: “igualdad entre quiénes?” (Bobbio 1993, p. 83). Peter Singer ha señalado, en este sentido, que "el principio de que todos los seres humanos son iguales es hoy parte de la ortodoxia ética y política dominante” (Singer 1984, p. 28, subrayado mío). ${ }^{9}$ Lo que no hemos resuelto es la segunda pregunta que Bobbio sugiere: “igualdad en qué?”. La solución de la primera cuestión reduce a dos las cuatro respuestas posibles que Bobbio sugería. Las dos que ahora quedan son: (a) igualdad entre todos los seres humanos en todo o (b) igualdad entre todos los seres humanos en algo (Bobbio 1993, p. 83).

Los problemas de $A$ y $A$

Ángeles y Aulis se casaron con la intención compartida de formar una familia numerosa. En algún momento Ángeles suscitó la cuestión de cómo deberían tratar a los hijos. Aulis respondió:

-"Es sencillo; lo único que deberemos hacer es tratarles a todos por igual".

Dos días después ella insistió:

-"Lo he estado pensando -dijo-y creo que no será suficiente tratarles a todos por igual; podría ocurrir que les tratásemos igual de mal".

Él, tras pensar un poco, concedió:

-"Creo que tienes razón. Lo que deberemos hacer es tratarles a todos igual de bien... desde luego, les llevaremos al mismo colegio, les compraremos el mismo tipo de ropa, les enseñaremos los mismos deportes... Naturalmente nos esforzaremos para proporcionarles todo lo que necesiten y se lo daremos a todos ellos por igual".

Unos días después, fue él quien reabrió la cuestión:

\footnotetext{
${ }^{8}$ Nótese que aquí Aristóteles no dice que la igualdad consista en igualdad para los iguales y desigualdad para los desiguales, sino que la justicia consiste en igualdad para los iguales y desigualdad para los desiguales (Vid. Ruiz Miguel 1994, p. 79). Cierto es, sin embargo, que cuando introduce la idea de igualdad geométrica da lugar a una idea muy ambigua de igualdad.

${ }^{9}$ Paul Barker atribuye la paternidad del principio de igualdad a Jefferson, lo que sería admisible sólo en un sentido político-institucional (Barker 2000, p. 11).
} 
- "Sigo dando vueltas al problema -dijo-. Pudiera ocurrir que alguno de nuestros hijos fuese más torpe, quizás incluso con alguna enfermedad o discapacidad... No estaría bien darle lo mismo que a los otros".

Ella contestó con rapidez:

- “iDesde luego! Yo daba por supuesto que tratarles a todos igual de bien no significaba darles lo mismo, sino dar a cada uno lo que necesitase para estar igual de bien que los demás, para vivir igual de bien, para ser igual de feliz..."

- "Me temo -apostilló Aulis- que no esté a nuestro alcance hacerles felices. Quizá lo único que podremos hacer es proporcionarles las mismas oportunidades de llegar a serlo".

De este modo Ángeles y Aulis rechazaron, primero, el principio “debemos tratar a todos nuestros hijos por igual" en favor del principio "debemos tratar a todos nuestros hijos igual de bien"; después, rechazaron éste en favor del principio "debemos dar a cada uno lo que necesite para estar igual de bien que los demás"; finalmente, rechazaron también éste en favor del principio "debemos tratar a todos nuestros hijos de forma que tengan las mismas oportunidades de llegar a estar igual de bien".

Ángeles y Aulis tuvieron, en efecto, cuatro hijos: Bruno, Cristina, Daniel y Elena.

Durante el mes de septiembre de 2003, un mes absolutamente corriente en su vida, Ángeles y Aulis realizaron, entre otras, las siguientes acciones.

(1) El jueves día 4, con ocasión de celebrar su aniversario de boda, invitaron a todos sus hijos a cenar en un restaurante caro $y$, en los postres, dieron a cada uno de ellos como regalo un cheque por 200 euros.

(2) El miércoles día 10, siguiendo las instrucciones del médico, gastaron 200 euros en medicinas destinadas a su hijo Bruno que habia contraído una infección gripal aguda. El mismo día regalaron a Cristina una motocicleta, que costó 3.600 euros, con motivo de haber terminado brillantemente sus estudios de secundaria. Los otros tres hermanos protestaron, entre bromas, alegando que nunca se habian hecho regalos tan caros; Ángeles y Aulis replicaron, con cierta seriedad, que nunca ninguno de los otros habia obtenido tan buenas notas.

(3) El viernes día 19 se celebró una reunión familiar para establecer el presupuesto dedicado al esqui durante el curso 2003-2004 (el esquí es el deporte preferido de los cuatro hijos). Ángeles y Aulis comunicaron que habian podido prever 60.000 euros para la temporada, pero que-teniendo en cuenta que en la temporada anterior Bruno, Cristina y Elena habian recibido cada uno de sus respectivos padrinos, como regalo de cumpleaños, un nuevo equipo completo y que los padrinos de Daniel habian fallecido hacía dos años en accidente de tráfico- había que deducir del presupuesto la cantidad de 1.200 euros para comprar un equipo nuevo a Daniel, por lo que el presupuesto restante era de 58.800 euros, correspondiendo a cada uno de los hijos la cantidad de 14.700 euros. Los hermanos de Daniel protestaron repetidamente y coincidieron en afirmar, sin éxito, que ellos no tenían ninguna culpa de que los padrinos de Daniel hubiesen fallecido.

(4) El miércoles día 24, a pesar de la fuerte oposición de sus cuatro hijos, Ángeles y Aulis decidieron que sólo Bruno y Daniel podrían asistir a la concen- 
tración en favor de la paz que se celebraría durante todo el fin de semana en un camping. Tras muchas discusiones, Ángeles y Aulis sostuvieron su decisión con el argumento de que la concentración podía resultar peligrosa para las chicas bajo muchos puntos de vista, incluida tanto la asistencia de gente poco deseable como la previsible intervención de la policía.

(5) El viernes día 26 Ángeles y Aulis otorgaron testamento -sin conocimiento de sus hijos-mejorando ${ }^{10}$ por partes iguales a Cristina y Elena en la previsión (de la que ellos estaban honradamente convencidos) de que sus posibilidades de desenvolvimiento laboral futuro eran mucho menores que las de sus hermanos por el mero hecho de ser mujeres.

Los cinco ejemplos cotidianos de las decisiones de A y A coinciden, según creo, con intuiciones muy comunes y no ofrecen ningún aspecto particularmente problemático, aunque podamos discrepar de alguna de ellas.

En el primer caso nos encontramos con un trato igual hacia todos los hijos que es lo que, a primera vista, esperamos que hagan los padres en ausencia de circunstancias especiales. Todos los hijos reciben la misma consideración y respeto y, en consecuencia, reciben idéntico trato e igual regalo. Es un sencillo ejemplo de lo que cabe denominar un trato igual. ${ }^{11}$

En el segundo caso nos encontramos con dos supuestos de trato desigual a favor, respectivamente, de B y de C. El trato desigual a favor de B consiste en gastar una cantidad en medicinas para él; como es natural ninguno de los hermanos protesta. Parece que a nadie se le ocurre que la igual consideración y el igual cariño requieran comprar medicinas para quien no está enfermo y, tampoco, compensar con una igual cantidad económica a quien no ha requerido medicinas. Parece, pues, que es fácilmente admisible que merece un trato desigual quien lo necesita; sin embargo es de destacar que, en este supuesto, el gasto extraordinario no implica - dado el nivel económico de una familia media europea (como es el de A y A, que son ambos profesores universitarios)- ningún sacrificio inmediato en el bienestar o en las expectativas de sus hermanos. Es muy probable que esta circunstancia haga particularmente no-problemática la situación. El trato desigual a favor de $\mathrm{C}$ sí genera ciertas protestas -aunque benévolas- del resto de los hermanos; que los padres hayan decidido premiar el brillante rendimiento escolar

${ }^{10}$ El Código Civil español, vigente en todos los territorios que no tienen Derecho Civil propio, distingue, cuando hay hijos o descendientes, tres tercios en la masa hereditaria: uno de "legítima estricta" que corresponde por partes iguales a todos los hijos o descendientes llamados por ello "herederos forzosos"; otro de "mejora" que el testador puede repartir a su gusto pero sólo entre los herederos forzosos (el viudo o la viuda tiene derecho, como legítima, al usufructo del tercio de mejora cuando concurre con hijos o descendientes); y, por fin, otro "de libre disposición" que el testador puede repartir como quiera y entre quien quiera.

${ }^{11}$ El trato igual puede ser, como en el ejemplo, un trato positivo o puede ser un trato negativo como ocurriría si A y A prohíben a todos sus hijos salir de casa el fin de semana anterior a los exámenes del trimestre. 
de $\mathrm{C}$ puede resultar arbitrario si no habían establecido una regla en este sentido y, probablemente, es esto lo que suscita su moderada indignación; posiblemente es moderada, también, porque ninguno de los hermanos tiene un rendimiento similar ni se les exige y porque presumen que, de llegar a tenerlo, probablemente recibirán un regalo similar. En todo caso, todos ellos admiten que $\mathrm{C}$ tiene un particular mérito y que la decisión está de algún modo justificada. Es de destacar, nuevamente, que el regalo no se traduce, en este supuesto, en ningún sacrificio inmediato en el bienestar o en las expectativas de los hermanos y, puesto que ninguno de ellos es patológicamente envidioso, esta circunstancia hace una vez más que la situación no resulte particularmente problemática.

El tercer supuesto es un poco más complicado. A y A establecen un trato desigual a favor de D. El motivo de ello es, sin embargo, situar a D en las mismas condiciones en que están B, C y E, es decir: igualar a D con sus hermanos. Como ya sabemos el motivo de la desigualdad en que se encuentra $\mathrm{D}$ no ha sido su propia conducta sino un desgraciado azar. Probablemente los hermanos no hubieran opuesto ninguna objeción si A y A, en lugar de ser profesores de universidad, hubiesen sido accionistas mayoritarios de una empresa farmacéutica y le hubiesen comprado el equipo sin necesidad de aquilatar gastos. Pero no ha sido así y la consecuencia es que el trato desigual para igualar a D supone un daño inmediato (aunque no sea muy grave) para $\mathrm{B}, \mathrm{C}$ y $\mathrm{E}$.

A la cuarta decisión se opusieron unánimemente todos los hijos, chicas y chicos. El aparente talante liberal de A y A parecía ceder, en este caso, ante ancestrales prejuicios de género, mezcla de temores infundados a la promiscuidad sexual, la violencia social y la presunta mayor debilidad física de las hijas. La decisión es claramente lo que llamamos un trato discriminatorio. Conviene señalar, sin embargo, que la discriminación de $\mathrm{C}$ y E, en este caso, representa un daño para ellas pero no representa ningún beneficio especial, ni ningún daño especial, para $\mathrm{B}$ y $\mathrm{D}$.

En la quinta decisión, por fin, nos encontramos de nuevo con un trato discriminatorio aunque, en esta ocasión, presenta dos rasgos totalmente distintos. En primer lugar, la discriminación no perjudica sino que favorece a las discriminadas; en segundo lugar la discriminación causa un perjuicio a B y D. Es fácil suponer que B y D, de haberlo sabido, se hubieran opuesto activamente a semejante decisión.

Los problemas escenificados de A y A no agotan ni remotamente los que podrían imaginarse pero son suficientes, según creo, para poner de relieve cómo - una vez que A y A han aceptado reflexivamente un principio de igualdad entre sus hijos que se traduce en "debemos tratar a todos nuestros hijos de forma que tengan las mismas oportunidades de llegar a estar igual 
de bien"- las circunstancias parecen requerir rápidamente tratos desiguales en atención a la necesidad, al mérito o incluso a supuestas características derivadas del estatus (en los ejemplos, del género), características estas últimas que podrían tratar de justificarse bien en razón de la aptitud (en el ejemplo, de la supuesta falta de aptitud) o bien en razón de la necesidad. Ponen de relieve, también, que junto a estos factores interviene uno que puede revestir gran importancia: si el trato desigual produce o no produce un daño (digamos, un daño emergente o un lucro cesante) en los demás.

El primer problema de la igualdad es, por tanto, el de los criterios que justifican o exigen un trato desigual cuando se quiere tratar a un conjunto de personas como iguales. Asumiré ahora sin mucha discusión que en la ortodoxia dominante estos "criterios de relevancia" para justificar tratamientos desiguales son los de la necesidad, el mérito, la capacidad (o aptitud) y el estatus. ${ }^{12}$ Pero no es éste el único problema. Aunque discrepemos de alguna de sus decisiones, ninguno pondremos en duda que son correctos tanto el valor que inspira la búsqueda de un principio como las decisiones para aplicarlo de A y A: pensamos todos, en efecto, que todos sus hijos son iguales, es decir: deben valer lo mismo para ellos o tienen derecho a ser tratados como iguales por ellos. No pensamos, sin embargo, que tengan el mismo igual valor, o el mismo derecho a ser tratados como iguales, sus sobrinos, los hijos de sus amigos o, con mayor motivo, los hijos de los desconocidos. Ello quiere decir que el principio de igualdad no es un principio de la ortodoxia ética dominante en todo su ámbito, sino exclusivamente de la ortodoxia dominante en el ámbito de la ética pública o política. Una concepción paternal del Estado ha sido, durante mucho tiempo, la precisa justificación de que el derecho a ser tratados como iguales se entendiese aplicable sólo a los ciudadanos. Una concepción universalista de los derechos humanos requiere, sin embargo, que el derecho a ser tratados como iguales se entienda como un derecho moral básico de cualquier persona. Aquí empieza el problema más serio, aunque no me ocuparé ahora de él. ${ }^{13}$

Conviene señalar, resumiendo, que si tomamos en cuenta que el trato desigual puede obedecer a diversos criterios justificativos, que puede ser positivo o negativo, y que puede causar o no causar daño a otros, y barajamos a la manera de Bobbio estos tres tipos de factores es fácil resumir las dieciséis decisiones posibles de trato desigual que A y A podrían tener que enfrentar:

${ }^{12}$ Vid. Laporta 1985, pp. 15 y 20, donde denomina a estos criterios como "principios de tratamiento diferenciado". Un buen análisis, del que parte Laporta, es el de Eckhoff 1974.

${ }^{13}$ Me he ocupado en Hierro 1995. 
Trato desigual

\begin{tabular}{|l|l|l|l|l|}
\hline & \multicolumn{2}{|c|}{ Sin daño } & \multicolumn{2}{c|}{ Con daño } \\
\hline Por necesidad & Positivo & Negativo & Positivo & Negativo \\
\hline Por mérito & Positivo & Negativo & Positivo & Negativo \\
\hline Por aptitud & Positivo & Negativo & Positivo & Negativo \\
\hline Por estatus & Positivo & Negativo & Positivo & Negativo \\
\hline
\end{tabular}

Lo único - cabe añadir- que A y A no podrían hacer, si asumen que hay criterios de relevancia, es pretender satisfacer mediante normas generales y abstractas el derecho de sus hijos a ser tratados como iguales porque cualquiera de los dieciséis supuestos exige una norma menos-que-general o menos-que-abstracta; lo que, en términos jurídicos, llamaríamos un "Derecho desigual". ${ }^{14}$

\section{Sobre la generalidad y abstracción de las normas y cómo el derecho a la igualdad requiere normas menos-que-generales o menos-que abstractas}

Pienso que casi nadie cree hoy que la generalidad y abstracción de las normas jurídicas o, al menos, de las normas jurídicas superiores -las "leyes"- sean caracteres ontológicos o definicionales de ellas. Respecto al debate clásico, Von Wright apuntó sabiamente lo siguiente:

"Por lo que respecta al término «ley», la disputa entre Austin y Blackstone me parece carente de interés. Podría ser, no obstante, una cuestión interesante de filosofía politica y de filosofía de la jurisprudencia, la de saber si no es esencial para la ley (o para el Estado) el que las leyes del Estado sean generales. La pregunta tendría entonces que relacionarse con nociones atinentes al propósito de las leyes y a la raison d'être de un estado" (G. H. Von Wright, 1979, p. 99)

Pienso, sin embargo, que muchos sí piensan que generalidad y abstracción son, como dijo Bobbio, caracteres ideales de las leyes, es decir: son caracteres de las leyes justas, porque la generalidad satisface el valor de la igualdad y la abstracción satisface el valor de la certeza, y ahí reside -dirían- la respuesta a la pregunta de Von Wright. Pero dudo seriamente de que sea ésta la respuesta correcta.

${ }^{14}$ En la Crítica al Programa de Gotha, Marx explicaba que el derecho burgués era formalmente igual pero que "en el fondo es, por tanto, como todo derecho, el derecho de la desigualdad"; como contrapartida Marx no proponía mayor igualdad jurídica, sino precisamente que "para evitar todos estos inconvenientes, el derecho no tendría que ser igual, sino desigual" (Marx [1891] 1968, p. 23). Atienza comentaba que era dudosa la viabilidad del proyecto de Marx ya que este Derecho "supondría - entre otras cosas- un sistema jurídico cuya base no fueran normas generales y abstractas, sino normas particulares y concretas" (Atienza 1983, p. 255, nota 169). 


\section{Historia del Rey Funes ${ }^{15}$}

Dos meses antes de morir, Ireneo Funes fue designado primer rey de la recién constituida Monarquía Igualitaria de la Patagonia. De acuerdo con el protocolo del reino, Funes juró solemnemente tratar a todos sus súbditos por igual. El rey Funes visitó la primera semana las cien aldeas de mil habitantes cada una que formaban el nuevo reino. Al volver de la visita recordaba perfectamente a sus cien mil súbditos, sus nombres, apellidos, rostros, estaturas, atuendos y, es más, recordaba a cada uno cada una de las veces que lo había percibido o imaginado; a unos los recordaba de seis formas, a otros de diecisiete y a sus ministros los recordaba ya en miles de formas y momentos.

Un día el primer ministro le dijo:

-"Rey, los habitantes de la Aldea del Norte piden que se les exima de pagar impuestos durante tres meses porque han sufrido una dura sequía. Te pido que apruebes una ley eximiéndoles".

El Rey contestó:

-"Querrás decir que debo aprobar mil leyes, una para eximir del pago a cada uno de ellos. Pero esto no es posible; he jurado tratar a todos por igual de modo que no puedo eximir de impuestos sólo a los habitantes de la Aldea del Norte. Así que eximiré a todos mis súbditos. Prepara cien mil leyes, una para Abel Abín, otra para Adela Acosta, otra para Antonio Aguado..."

y continuó recitando la lista de sus súbditos hasta que el ministro le sugirió que él mismo consultaría el censo. Al día siguiente firmó las cien mil leyes.

Dos días después el primer ministro le dijo:

-"Rey, hay cuatro niños en la Aldea del Sur que han contraído una grave enfermedad que sólo puede tratarse con una costosa medicina de importación. Te pido que apruebes cuatro leyes -el ministro creyó haberle cogido el tranquillo al Rey- concediéndole a cada uno el derecho a la medicina y ordenando al Gobierno que la adquiera para entregársela."

Respondió el Rey:

-"Ya sabes que esto no es posible, he jurado tratar a todos por igual de modo que no puedo dar la medicina a estos cuatro niños nada más, así que se la daremos a todos los súbditos. Prepara cien mil leyes, una para Abel Abín, otra para Adela Acosta, otra para Antonio Aguado ..."

Y las preparó y se firmaron, publicaron y cumplieron.

Pocos días después el ministro le dijo:

-"Rey, en la Aldea del Este un tal Zenón Zaforas está robando ganado. Te pido que dictes una ley prohibiendo robar ganado y condenando a todo el que lo haga a la pena de diez años de cárcel. Esta ley -se adelantó agudamente el ministro- se la aplicaremos a Zaforas si vuelve a robar y a cualquier otro si también lo hace."

-“¡Ah! Eso está bien visto - dijo el Rey- pero sigo sin entender esa manía que tienes de hacer una sola ley ignorando que cada uno de mis súbditos es un individuo distinto y separado. Hay que dar a cada uno su Derecho y por tanto

${ }^{15}$ Fue Francico Laporta, hace unos años, en el borrador de un trabajo sobre conceptos jurídicos que no llegó a publicarse, quien llamó mi atención sobre este espléndido cuento de Borges que ahora me permito continuar a mi modo. El personaje (Funes el memorioso) y las dos frases subrayadas en mi cuento son originales de Borges. 
prepararás cien mil leyes. La primera dirá "Si Abel Abín roba ganado, será condenado a diez años de cárcel"; la segunda dirá "Si Adela Acosta roba ganado, será condenada a diez años de cárcel", la tercera dirá "Si Antonio Aguado roba ganado, será condenado a diez años de cárcel"...

y continuó su lista hasta que el ministro se fue a preparar las cien mil leyes.

A los dos meses del reinado de Funes, el Gran Lord del Sello decidió convocar a la Asamblea para deponer al Rey y le formuló dos preguntas:

-“¿Es nuestro Rey Funes igualitario?”

La Asamblea respondió por unanimidad que sí.

-“¿Es nuestro Rey Funes justo?”

La Asamblea respondió por unanimidad que no.

Como la Constitución preveía deponer al Rey si no era igualitario pero no preveía deponerle si no era justo, el Gran Lord, que era el único que había estudiado en Oxford, improvisó una tercera cuestión con distinto ajuste constitucional:

-“¿Está nuestro Rey bien de la cabeza?”

La Asamblea respondió por unanimidad:

-"No, es idiota".

Y lo depusieron. Ireneo Funes murió en 1889, de una congestión pulmonar.

Muchos autores se han ocupado de la posibilidad de convertir normas singulares en normas formalmente generales. Enseguida me ocuparé de ello. Me parece que es menos frecuente haber prestado atención a la obviedad que la "Historia del Rey Funes" pone de relieve: la posibilidad de convertir normas generales, absolutamente generales, en normas singulares. ${ }^{16} \mathrm{Si}$ uno quiere prescribir la conducta $\mathrm{C}$ para un conjunto de sujetos $\mathrm{S}$, puede dictar una norma general que diga "Todos los $\mathrm{S}$ deben $\mathrm{C}$ " o puede dictar tantas normas singulares como sujetos $\mathrm{S}$ haya, que digan cada una de ellas: "S1 debe C", "S2 debe C" ... Obviamente el único inconveniente es que tiene que conocer a todos los $\mathrm{S}$ del conjunto y que el conjunto, por grande que sea, ha de ser cerrado. Cada vez que aparece un nuevo $\mathrm{S}$ el edictor tiene que promulgar una nueva norma. Si todas las normas establecen la misma conducta para todos los sujetos (da igual, obviamente, que hablemos de una prohibición, una obligación, un permiso, la atribución de una competencia, etc.) todos los sujetos son tratados normativamente exactamente del mismo modo, son iguales ante la ley. La singularidad de las normas no impide, en absoluto, la igualdad de trato. El problema de la singularidad de las normas

\footnotetext{
${ }^{16}$ Hernández Marín sostiene que todos los enunciados jurídicos individuales son reducibles a algún enunciado jurídico general, mientras que sólo algunos enunciados jurídicos generales son reducibles a enunciados jurídicos individuales; otros enunciados jurídicos generales no son reducibles a enunciados individuales y estos son propiamente los enunciados generales $o$ generales no reducibles a individuales (Hernández Marín 1989, p. 68).
} 
no estriba en la desigualdad, sino en la estupidez. Hay una doble estupidez. Por un lado, es un trabajo tan ímprobo como inútil el que el Rey Funes encomendaba a su primer ministro. El pensamiento consiste en abstraer y el pensamiento del que crea normas consiste en abstraer normas. ${ }^{17} \mathrm{Si}$ uno quiere que todos los $\mathrm{S}$ hagan $\mathrm{C}$, es más racional decir que "Todos los $\mathrm{S}$ deben C" que dictar una norma de este tenor para cada uno de los S. Por otro lado, la formulación racional de la norma, en términos generales, permite preestablecer que cualquier futuro $\mathrm{S}$ haga $\mathrm{C}$, es decir: permite abrir el conjunto para integrar en él a todo posible miembro que reúna las características de los S; el conjunto se convierte así en un conjunto abierto, no determinado pero determinable.

El cuento, por cierto, no es tan irreal como pueda parecer. En los albores del Estado moderno el Derecho era, en los reinos de España como en toda Europa, de marcado carácter localista; cada ciudad tenía su fuero, cada estamento su privilegio ("ley privada", en su sentido textual). Cuando los reyes empezaron a tratar de consolidar los reinos como entidades políticas separadas, a ser "emperadores en sus reinos", procuraron la homogeneización del Derecho y alguno recurrió, para ello, a conceder el mismo fuero a diferentes ciudades; en Castilla, por ejemplo, el rey Fernando III, el año 1222, confirmó y extendió la vigencia del derecho municipal de Toledo, que estaba principalmente constituido por el Liber Iudiciorum (un código del siglo VII), propiciando su traducción al castellano que se publicó bajo el nombre de Fuero Juzgo y concediéndolo como "fuero" a un gran número de ciudades (Tomás y Valiente 1979, pp. 162-163). Así que Fernando III, como el Rey Funes, hizo muchas leyes singulares con el mismo contenido.

Tengo la impresión también de que algo muy parecido a esta exigencia de racionalidad es lo que tenía en mente Juan Jacobo Rousseau que, cuando sienta con tanto éxito la tesis de que las leyes han de ser generales, parece estar más preocupado por la racionalidad de su formulación que por la igualdad de su contenido. Al menos eso cabe deducir de sus propias palabras:

"Cuando digo que el objeto de las leyes es siempre general, entiendo que la ley considera a los súbditos en cuanto cuerpos y a las acciones como abstractos: nunca toma a un hombre como individuo ni una acción particular. Así, la ley puede estatuir muy bien que habrá privilegios; pero no puede darlos especialmente a nadie. La ley puede hacer muchas clases de ciudadanos y hasta señalar las cualidades que darán derecho a estas clases; más no puede nombrar a éste o aquél para ser admitidos en ellas; puede establecer un gobierno real y una sucesión hereditaria, mas no puede elegir un rey ni nombrar una familia real: en

\footnotetext{
17 "Pensar es olvidar diferencias, es generalizar, abstraer" (Borges 1993, p. 17).
} 
una palabra, toda función que se relacione con algo individual no pertenece al Poder legislativo." (Rousseau [1762] 1969, pp. 50-51, subrayados míos) ${ }^{18}$

¿Cómo se puede establecer un gobierno real y una sucesión hereditaria sin elegir un rey y nombrar una familia real? El artículo 57 de la vigente Constitución Española se redactó, por cierto, sin contar con Rousseau, por lo que dice: "La Corona de España es hereditaria en los sucesores de S.M. Don Juan Carlos I de Borbón, legítimo heredero de la dinastía histórica." Si se hubiese redactado contando con Rousseau, debiera haber dicho: "La Corona de España es hereditaria en los sucesores del ciudadano que resulte ser legítimo heredero de la dinastía histórica." Como en España siempre ha habido alguna discusión dinástica pendiente quizás debiera haberlo aclarado diciendo "de la dinastía histórica que haya reinado por última vez" o algo así. Yo no creo, por supuesto, que la norma sea más general con la segunda redacción que con la primera porque establece lo mismo; desde luego, tampoco creo que sea más ni menos injusta en una forma que en otra, porque establece lo mismo.

Peter Westen ha discutido con particular claridad la posibilidad de convertir normas singulares en normas generales. En los términos de Westen, la diferencia estriba en formular la norma utilizando una clasificación de un solo rasgo (single-trait) o de múltiples-rasgos (multiple-trait). Si tomamos una norma como "P3 Todo ciudadano tiene el derecho de pedir al gobierno la reparación de agravios", esta norma se puede formular con un solo rasgo o con múltiples rasgos. En el primer caso la norma dirá: "P3 Todo ciudadano tiene el derecho de pedir al gobierno la reparación de agravios"; en el segundo caso, dirá: "P3' Toda persona que sea un ciudadano tiene el derecho de pedir al gobierno la reparación de agravios" (Westen 1990, p. 81). Naturalmente, Westen no pretende que de aquí se derive ninguna consecuencia importante.

“Sustantivamente, P3 y P3' son idénticas produciendo los mismos resultados normativos en cualquier caso. Formalmente, sin embargo, difieren significativamente. P3 crea una sola clase general de "ciudadanos" cuyos miembros son

${ }^{18}$ Aun cuando la libertad republicana requiere, en Rousseau, una igualdad positiva o igualdad como ciudadanos y una cierta igualdad de condiciones (ni demasiado ricos ni demasiado pobres), es patente que los requisitos de generalidad y abstracción de la ley no se conectan tanto con el valor de la igualdad como con un alambicado concepto de ley como voluntad general, conforme al cual el todo no puede legislar para una parte porque, en tal caso, ya no sería el todo sino el todo menos una parte y esto no es el todo (ibídem, p. 50). Sin embargo la ley puede establecer diferencias e incluso privilegios. Esta peculiar ontología de la ley tuvo, como es sabido, una extensa influencia en el positivismo clásico para el cual la ley era necesariamente general y abstracta, aunque fuese para regular "en general" situaciones concretas o incluso para conceder "en abstracto" privilegios (sobre el alcance de la igualdad en Rousseau vid., Maurice Cranston 1985, passim). 
prescriptivamente iguales sin ser en ningún aspecto prescriptivamentre desiguales. P3', en contraste, crea una clase general de "personas" y una subclase de "ciudadanos". Ahora los miembros de la clase general son al mismo tiempo prescriptivamente iguales y prescriptivamente desiguales - iguales porque todos ellos poseen el privilegio de pedir al gobierno la reparación de agravios $\underline{\mathrm{si}}$ pueden demostrar que son ciudadanos, desiguales porque sólo los ciudadanos poseen tal privilegio.

La relación entre P3 y P3' es significativa porque sucede que cualquier regla de la forma P3 puede reformularse como P3'. En otras palabras, toda regla que crea derechos o deberes en las personas que poseen un rasgo singular, $X$, puede reformularse como si creara derechos y deberes dentro de una clase inicial de "personas" que posean además el rasgo adicional prescrito $X$. En ese sentido, todas las personas son iguales bajo todas las reglas morales o jurídicas, porque en cuanto "personas" tienen todas ellas los derechos y deberes prescritos si pueden demostrar que poseen cualesquiera rasgos adicionales que las reglas puedan requerir. Pero al mismo tiempo las personas son también desiguales bajo la mayor parte de las reglas morales o jurídicas porque la mayor parte de las reglas también distinguen entre las personas tratando a aquellos que poseen rasgos particulares de modo diferente a quienes no los poseen" (ibídem, pp. 81-82).

El argumento de Westen me parece irrefutable. ${ }^{19}$ Hace unos años he discutido con Manuel Atienza y con Javier de Lucas la justificación (o falta de justificación) del artículo 14 de la Constitución Española, que dice: "Los españoles son iguales ante la ley..." Supongo que nadie pretenderá que nuestros respectivos argumentos sobre la cuestión tuvieran que cambiar si el artículo se modificase para decir: "Todas las personas que sean españolas son iguales ante la ley".

Las normas generales pueden formularse como normas singulares sin que esto quite ni ponga nada al igual o desigual tratamiento de sus destinatarios. Las normas singulares pueden formularse como normas generales sin que esto quite ni ponga nada al igual o desigual tratamiento de sus destinatarios. La generalidad, mayor o menor, de las normas tiene poco que ver con la igualdad. Sí tiene que ver, sin embargo, con la racionalidad lingüísticonormativa y con la posibilidad de regular la conducta de sujetos u ocasiones posibles, lo que sólo puede hacerse mediante generalización y abstracción. Por ello tiene que ver con la predecibilidad normativa y, en consecuencia, tiene que ver con la seguridad jurídica y, de este modo, tiene mucho que ver con la justicia. Pero no por el camino de la igualdad, sino sólo por el camino de la seguridad y, a través de ella, de la libertad..$^{20}$

${ }^{19}$ El mismo argumento, aunque menos explicado, es el de Hernández Marín sobre la irrelevancia de la distinción normas individuales/normas generales (Vid. supra nota 16).

${ }^{20}$ Puedo ahora aclarar la discrepancia con Bobbio que anuncié al principio (supra nota 4): la generalidad y la abstracción sirven, ambas, a la certeza; ninguna de ellas a la igualdad. 


\section{Sobre la justificación razonable de los tratamientos desiguales}

Asumí antes que los criterios relevantes, moralmente relevantes, para el tratamiento desigual de sujetos que tienen derecho a ser tratados como iguales (o a los que se debe tratar como iguales) son cuatro. Cada uno de ellos tiene una justificación distinta y opera en distinto ámbito. Repetiré ahora lo que, de forma muy sucinta, he sostenido en trabajos anteriores tratando de enunciar el derecho a la igualdad:

"Todo ser humano tiene derecho a un igual trato legal y a unas iguales oportunidades para desenvolverse como agente moral. (1) La diferenciación por rasgos distintivos relevantes sólo procede cuando la no discriminación por rasgos irrelevantes está satisfecha. (2) La diferenciación en resultados sólo procede cuando la igualdad en oportunidades está satisfecha. (3) Una sociedad, sus normas e instituciones, satisfacen el derecho a la igualdad cuando sus posiciones y bienes están abiertos a todos en virtud del principio de no discriminación $y$ de igualdad de oportunidades y sólo establece tratos desiguales en virtud de criterios relevantes y adecuados al caso, a saber: (3.1) el criterio de necesidad vale para diferenciar en la igualación de oportunidades y en la redistribución de resultados; (3.2) el criterio de mérito vale para atribuir premios, recompensas y castigos a las acciones voluntarias y en la atribución de resultados; (3.3) el criterio de aptitud vale para atribuir cargos y funciones que no sean representativas; (3.4) el criterio de status vale sólo si es reducible a alguno de los anteriores, e incluye la discriminación inversa en función de la igualación en oportunidades." 21

En la medida en que el principio de igualdad entre todos los seres humanos es un principio relativo al sujeto pero no relativo a la ocasión, se hace

Hay, no obstante, un aspecto casi trivial en que la mayor generalidad tiene algo que ver con la igualdad: si una norma tiene como destinatario un conjunto muy amplio de sujetos (es muy general, en el sentido en que vengo hablando) obvio es concluir que da igual tratamiento a ese amplio número de sujetos.

21 "Sólo procede" debe entenderse aquí como una aserción en el plano moral; significaría que "sólo tiene una justificación moral completa". Por supuesto la imperfección de las estructuras sociales reales y la dinámica de la realidad hacen imposible cualquier pretensión de suspender toda diferenciación en resultados (en razón del mérito) hasta que haya una perfecta igualdad de oportunidades. Lo que el principio expresa es que tal diferenciación en resultados no tendría una justificación moral completa en tanto en cuanto no se diera una perfecta igualdad de oportunidades. No parece inútil tener claro quiénes son moralmente los deudores y quiénes los acreedores en una sociedad en la que no se haya podido llegar a cancelar toda discriminación por rasgos irrelevantes $\mathrm{y} / \mathrm{o}$ no se haya podido satisfacer perfectamente la igualdad de oportunidades.

Estos enunciados se basan principalmente en el análisis de Laporta 1985, pp. 20-27. En particular el principio (1) de que "la diferenciación basada en rasgos distintivos relevantes procede sólo cuando la no discriminación por rasgos irrelevantes está satisfecha" fue textualmente enunciado por él (ibídem, p. 26). He desarrollado un principio similar (2) para la relación resultados-oportunidades. El enunciado general del principio (3) es también suyo aunque he añadido a la condición de no-discriminación la condición de igualdad-de-oprtunidades. 
imposible sostener para su implementación un principio como el que, respecto a la libertad, implica el imperativo categórico, es decir: no es posible sostener que la igualdad de cada uno sólo está limitada por la "igual" igualdad de los demás. Si ello fuera posible, se traduciría exclusivamente en que la igualdad sólo permitiría diferenciaciones tendentes a igualar a los que están peor con los que están mejor. En términos constitucionales diríamos: el artículo 14 de la Constitución Española sólo permite diferencias legales que estén requeridas por su artículo 9.2. ${ }^{22}$ No conozco a nadie, ni siquiera entre los igualitaristas más radicales, que sostenga que lo único que justifica un tratamiento desigual es la igualdad misma; ${ }^{23}$ ello implicaría sostener que, en el ejemplo de A y A, sólo el supuesto 3 estaba justificado. Todo el mundo admite, por el contrario, que a la hora de atribuir premios y castigos el criterio relevante es el del mérito, aun cuando la aplicación del criterio no tiende a igualar a los que tienen menos méritos con los que tienen más méritos; igual sucede con el criterio de la capacidad o aptitud; sólo el criterio de necesidad podría someterse al principio de diferencia y nadie piensa sensatamente que sea éste el único criterio justificativo de tratamientos desiguales. ${ }^{24}$ Esa es la

${ }^{22} \mathrm{El}$ artículo 14 dice: "Los españoles son iguales ante la ley, sin que pueda prevalecer discriminación alguna por razón de nacimiento, raza, sexo, religión, opinión o cualquier otra condición o circunstancia personal o social." El artículo 9.2 dice: "Corresponde a los poderes públicos promover las condiciones para que la libertad y la igualdad del individuo y de los grupos en que se integra sean reales y efectivas; remover los obstáculos que impidan o dificulten su plenitud y facilitar la participación de todos los ciudadanos en la vida política, económica, cultural y social."

${ }^{23}$ La obra más reciente que conozco en defensa de un igualitarismo radical es la del canadiense Kai Nielsen (Nielsen 1985). No niega, sin embargo, la virtualidad de los principios de mérito y aptitud (ibídem, pp. 106, 109, 112, 128, 130 y 177). Respecto al criterio general, que vendría a ser el de la necesidad o capacitación, lo más llamativo en la obra es su constante ritornello a la Crítica al Programa de Gotha cuando, una y otra vez, diseña como condición necesaria de una sociedad igualitaria-radical el contexto de una sociedad de abundancia. Sobre el sentido y los límites de esa condición vid. Laporta 1985, p. 28 y Hierro 2002, pp. 9-10.

${ }^{24}$ Laporta ofrece un análisis breve pero lúcido de los cuatro "principios de tratamiento diferenciado”, necesidad, mérito, aptitud y estatus (Laporta 1985, pp. 20-27), señalando que no son exhaustivos, que su interpretación depende del contexto sociocultural lo que les hace variables, que son graduales y que pueden ser conflictivos entre sí. Suscita también la cuestión de si son propiamente principios de igualdad o principios de justicia, cuestión en la que yo -como ya he insinuado citando a Aristóteles- me adhiero a la segunda tesis.

La literatura general sobre estos criterios es inmensa, sin embargo su estudio monográfico es más bien escaso salvo para el criterio de mérito. Además de que el criterio de mérito está en la base de la teoría penal de la acción, su utilización privilegiada junto a una concepción meramente formal de la igualdad de oportunidades es la base de toda concepción meritocrática (su crítica más lograda es el conocido libro de Michael Young, The Rise of the Meritocracy, de 1958). El criterio de necesidad ha empezado, recientemente, a ser objeto de una reconstrucción teórica (Len Doyal y Ian Gough, A Theory of Human Needs, de 1991 y, en España, Ma José Añón, Necesidades y derechos, de 1994). El único intento que conozco de un estudio detallado 
razón -es fácil suponer- de que los tribunales constitucionales ni siquiera se hayan planteado la idea de que los tratamientos desiguales sólo puedan ser constitucionales si tienden a fomentar la igualdad.

Una segunda aproximación podría sostener que sólo un valor político fundamental (es decir: un valor o principio constitucional) puede justificar un tratamiento desigual. Esto implicaría, por ejemplo, que sólo el derecho a la vida justifica castigar como homicidas a todos los que matan a otro y sólo a los que matan a otro, pero que no habria justificación alguna para castigar como furtivos a los cazadores que matan animales durante la veda y sólo a ellos en cuanto -hoy por hoy- las crías de los animales no son titulares de derechos fundamentales. De acuerdo con esta aproximación resultaría admisible en España diferenciar por mérito y capacidad para acceder a la función pública, puesto que la Constitución Española en su artículo 103 menciona estos criterios para dicho ámbito, pero no sería posible que el legislador exigiera un determinado título académico para trabajar como agente de la propiedad inmobiliaria ya que no se trata de una función pública. También esta aproximación ha sido desechada por los tribunales constitucionales.

Los tribunales constitucionales coinciden en exigir, para justificar constitucionalmente los tratamientos desiguales, un criterio mucho más débil y mucho más formal. Suele traducirse en la elusiva idea de que el tratamiento diferente sea "razonable". ${ }^{25}$ Digo que la idea es elusiva porque el criterio de "razonabilidad", por más esfuerzos que se han hecho para depurarle de vaguedad, termina por convertirse en un criterio meramente formal. Se trata, en definitiva, de que quien está autorizado para establecer un tratamiento diferenciado (en primer lugar, el legislador) sea capaz de aducir justificaciones objetivas y razonables para hacerlo. Cuando digo que es elusiva no digo, sin embargo, que sea en ningún modo inútil.

y conjunto de estos criterios sería el de Michael Walzer en Spheres of Justice, de 1983. La gran aportación de Walzer es, en mi opinión, la demostración de que la igualdad es un valor complejo que requiere la utilización de criterios diferentes para esferas diferentes. Sin embargo me parece que el libro adolece de una demostración mínimamente sistemática de cuáles son las razones que sustentan el criterio que debe regir en cada esfera, defecto que, con toda seguridad, es el precio del "comunitarismo" de Walzer que le conduce a una conclusión tan desilusionante como ésta: "Así como es posible describir un sistema de castas que cumpla con los parámetros (internos) de la justicia, es posible describir un sistema capitalista que cumpla con la misma finalidad" (Walzer 1993, p. 324).

${ }^{25}$ Sobre la doctrina del Tribunal Constitucional Federal alemán puede verse Robert Alexy 1993, pp. 388-402. Es suficiente ahora señalar que "El Tribunal Constitucional Federal subraya reiteradamente que, en el ámbito de la igualdad de tratamiento, el legislador dispone de «una muy amplia libertad de configuración»" (ibídem, p. 393) en la que el único límite es que no se trate de un tratamiento desigual arbitrario, es decir: carente de razón "razonable" (ibídem, p. 395). 
El Tribunal Constitucional español ha depurado bastante la idea de razonabilidad llegando a consolidar una doctrina que, según creo, podría resumirse en un requisito general y ciertos requisitos especiales:

(1) Razonabilidad: un tratamiento desigual debe ser razonable para ser constitucional. La razonabilidad es algo más que la pura deducción y algo menos que la optimización política: ninguna diferenciación no-razonable es constitucional pero toda diferenciación razonable es constitucional.

(1.1) Objetividad: un tratamiento desigual debe corresponder a una situación fáctica diferente. El tratamiento desigual no puede responder exclusivamente a características del sujeto sino a circunstancias u ocasiones en que el sujeto se encuentra o a relaciones entre características y situaciones .

(1.2) Finalidad: un tratamiento desigual tiene que perseguir una finalidad razonable. La mera objetividad no garantiza por sí sola la razonabilidad.

(1.3) Adecuación: un tratamiento desigual tiene que ser adecuado a la finalidad pretendida.

(1.4) Proporcionalidad: un tratamiento desigual tiene que mantener una proporción entre el tratamiento desigual y la finalidad.

Exigir el pago de una contribución especial sólo a los habitantes de los números pares de las calles para financiar las vacaciones del alcalde satisface el requisito de objetividad pero no el de finalidad, ${ }^{26}$ exigir el pago de una contribución especial sólo a los habitantes de los números pares de las calles para financiar la ayuda al desarrollo satisface los requisitos de objetividad y finalidad, pero no el de adecuación; condenar a muerte a todos los que aparquen indebidamente satisface los requisitos de objetividad, finalidad y adecuación pero no el de proporcionalidad.

La objetividad, la adecuación y la proporcionalidad no me parecen requisitos muy problemáticos aunque adolezcan de cierta vaguedad. El núcleo del problema se centra en la finalidad, es decir: en la justificación de la diferente consecuencia jurídica que se establece ante una desigualdad fáctica. Me parece que, en este aspecto, la jurisprudencia constitucional lo único que requiere es que la finalidad tenga una justificación pública admisible en el marco constitucional; es decir: que no sea arbitraria y que no sea directamente anticonstitucional (racista, sexista, etc.). Ello supone que

${ }^{26}$ La objetividad es claramente dependiente de la finalidad de tal modo que la finalidad justifica la objetividad pero nunca a la inversa. Es frecuente citar como ejemplo de desigualdad objetiva justificada la de requerir la condición de ser de raza negra para desempeñar un papel de "persona de raza negra" en una obra de teatro. Aquí la finalidad justifica la objetividad del trato desigual. Si un Ayuntamiento crease un cuerpo de policías de raza negra sin ninguna razón funcional, sino por meras razones "estéticas" (como Franco creó la "Guardia Mora" como recuerdo colonial), la falta de razonabilidad de la finalidad no quedaría justificada por la objetividad del diferente color de la piel. 
el legislador tiene un amplio margen para utilizar, en atención a diferencias fácticas diversas, los criterios de necesidad, de mérito, de aptitud y, con más restricciones, de estatus. ${ }^{27}$ Esto permite, en consecuencia, justificar constitucionalmente el establecimiento de escalas progresivas en la imposición directa, la concesión de privilegios fiscales para determinados sectores productivos o para los habitantes de zonas deprimidas, el otorgamiento de ayudas especiales para deportistas de alto nivel, la imposición de penas reforzadas para los delincuentes reincidentes, la reserva de puestos de trabajo para discapacitados, la imposición de cuotas femeninas en las listas electorales, etc. etc. En definitiva - como señala Alexy- existe una asimetría entre el principio de igualdad y los principios de tratamiento diferenciado que se traduce en "un principio de igualdad que, prima facie, exige un tratamiento igual y sólo permite un tratamiento desigual si puede ser justificado con razones opuestas" (Alexy 1993, p. 398).

Cuando se admite que entre la argumentación moral y la argumentación jurídica existen importantes diferencias, no hay inconveniente en admitir la enorme dosis de vaguedad que las exigencias de la jurisprudencia constitucional implican. Es muy plausible que, con los mismos requisitos jurisprudenciales de objetividad, finalidad, adecuación y proporcionalidad, se hubiese podido justificar hace algunas décadas la inadmisión de las mujeres en los ejércitos y en la policía; como es plausible pensar que con los mismos requisitos jurisprudenciales no se pueda justificar, dentro de algunas décadas, que las uniones heterosexuales y las uniones homosexuales tengan distinto tratamiento legal. Como dice Laporta, "la remisión al contexto social, cultural y lingüistico se hace necesaria para descubrir la mayoría de los criterios de uso de tales nociones. Esto tiene una importancia apenas disimulada, porque supone que la determinación de la existencia de esos rasgos diferenciales es por necesidad algo variable, evolutivo en el tiempo, ligado de algún modo al desenvolvimiento de las pautas culturales de la comunidad" (Laporta 1985, p. 25). Esto es una ventaja para la jurisprudencia constitucional, que puede asumir la constitucionalidad de los tratamientos desiguales en un ámbito vagamente determinado, y una ventaja para el legislador, que puede remitirse a criterios sociales variables que él interpreta. Pero no es una ventaja para el filósofo del Derecho; él tiene que revisar y afinar la justificación de cada uno de ellos, su ámbito y sus límites. Para él la razonabilidad no es un requisito a satisfacer, sino un horizonte a alcanzar.

Un aspecto especial de la razonabilidad del tratamiento desigual es el que se plantea en la llamada "igualdad en la aplicación de la ley", que tam-

${ }^{27}$ Vid. supra nota 25 sobre la doctrina del Tribunal Constitucional Federal alemán. La doctrina del Tribunal Constitucional español es exactamente la misma en este punto. 
bién ha sido acogida como exigencia del artículo 14 por la jurisprudencia constitucional española. Si el marco de la razonabilidad de los tratamientos desiguales por parte del legislador adolece de vaguedad, el marco de la pretendida razonabilidad de los tratamientos desiguales por parte de las decisiones judiciales ha terminado por resultar un puro formulismo.

El joven juez

Un joven juez le consultó al viejo magistrado:

-"Señor, he aprendido que la igualdad en la aplicación de la ley me exige resolver igual todos los casos que sean iguales. Pero no concibo cómo puede haber dos casos iguales."

-"No hay dos casos iguales, muchacho, sino cientos de miles. Los casos son iguales cuando sus aspectos legalmente relevantes son iguales. Y por cierto que no se trata propiamente de una cuestión de igualdad. Un antiguo jurista de la vieja Europa llamado Hans Kelsen decía que si dos casos caen bajo la misma ley, hay que aplicarles la misma ley y que eso es una cuestión de simple aplicación de la ley."

-"Pero, Señor," -insistió el joven juez- "¿qué hago si, después de haber aplicado la ley del mismo modo en diez casos legalmente iguales, en el undécimo caso legalmente igual descubro que me estaba equivocando?"

-"Es sencillo, muchacho. En primer lugar debes tratar de encontrar alguna diferencia legalmente relevante en el caso undécimo, lo que no es nada difícil; si, a pesar de todo, no la encontraras, puedes decir que el contexto social en que aplicas la norma es ahora distinto. Lo importante es esto: que inventes alguna razón para cambiar de criterio y que procures no decir que antes te has equivocado."

De acuerdo con la jurisprudencia constitucional española la igualdad en la aplicación de la ley no exige que dos órganos judiciales distintos resulevan del mismo modo casos iguales; esto, a lo sumo, es una cuestión de mera legalidad a resolver, en su caso, por el Tribunal Supremo. La igualdad en la aplicación de la ley tampoco exige que el mismo órgano judicial resuelva siempre del mismo modo dos casos iguales. En este caso lo único que el Tribunal Constitucional requiere es que, si un mismo órgano judicial resuelve de forma distinta un caso sustancialmente igual a otro resuelto anteriormente, aporte algún "fundamento suficiente y razonable" para hacerlo (STC 63/84, fundamento jurídico $2^{\circ}$ ). ${ }^{28}$ El requisito se traduce obviamente en una mera formalidad ya que el Tribunal Constitucional, en aras de la

${ }^{28}$ La jurisprudencia constitucional española ha evolucionado desde la STC 8/81 que sostuvo que "la igualdad ante la ley quiebra cuando dos supuestos semejantes se sitúan ante una misma norma jurídica y reciben tratamiento diferente” hasta las STC 49/82, 63/84 y 144/88 que, en aras de la independencia judicial, han establecido que la igualdad en la aplicación de la ley no exige que todos los órganos judiciales decidan igual casos semejantes, ni que un mismo órgano judicial no pueda cambiar de doctrina. Como señala Martínez Tapia la doctrina constitucional sentada implica "admitir que, para un mismo supuesto de hecho, puede haber varias soluciones jurídicas correctas” (Martínez Tapia 2000, p. 139). 
independencia judicial, no entra en estos casos a escrutar si el fundamento es verdaderamente razonable en cuanto a finalidad, adecuación o proporcionalidad.

\section{Sobre la llamada crisis de la ley y lo poco que tiene que ver con la igualdad}

El tópico de que las leyes han dejado de ser expresión racional del Derecho en cuanto han dejado de ser reglas abstractas y generales, convirtiéndose en meros actos de conformación política, fue ya enarbolado, no por primera vez, en un conocido discurso rectoral de Otto Bachof de 1959 (Bachof 1985). Tal argumento iba entonces, como suele ir ahora, acompañado de un llamamiento al juez para que restablezca "los valores superiores del Derecho".

Que es un requisito de racionalidad de las leyes su formulación en forma general y abstracta es algo que creo haber dejado ya claro. Tan claro como que el derecho de las personas a ser tratados como iguales requiere tratamientos desiguales cuando la ocasión lo requiere, incluyendo la ocasión de situar a las personas en igualdad de condiciones. Una norma no es justa por el mero hecho de ser general y abstracta y una norma no es injusta por el mero hecho de ser singular y concreta. Incluso una ley absolutamente singular y absolutamente concreta -y que, como tal, no contenía propiamente una norma, sino que más bien era una ley-medida o ley-mandato- como fue en España la Ley de Expropiación de Rumasa puede ser, como en mi opinión lo fue ésta, perfectamente justa.

Creo que bajo el rótulo "crisis de la ley" se encierra más bien la crisis de un cierto concepto de ley que la crisis de la institución misma de la legislación. He expuesto en otro lugar (Hierro 1996) que los motivos de esta crisis son cuatro: (1) la diversificación de la ley y la competencia entre diversos tipos de leyes, (2) la aparición de normas no legales de carácter paralegal ${ }^{29}$ en los procesos de integración regional de los estados, (3) la expansión de la fuerza normativa de las constituciones y (4) la expansión de la fuerza normativa de los principios. Estos cuatro factores afectaban de forma distinta tanto a lo que allí denominé "concepción débil" del imperio de la ley como a la "concepción fuerte", a la que yo me adhería. ${ }^{30}$

\footnotetext{
${ }^{29}$ Denomino "normas no legales de carácter paralegal” a las Directivas y Reglamentos comunitarios que prevalecen sobre la legislación estatal.

${ }^{30}$ Entendía allí por "concepción débil" la que sólo requiere que leyes satisfagan ciertos requisitos estructurales (competencia, generalidad, no retroactividad y publicidad) y por "concepción fuerte" a la que, además, requiere que satisfagan el principio democrático.
} 
Reproduciré ahora las conclusiones a las que entonces llegaba y que, por el momento, no he encontrado razón alguna para rectificar:

-(1) La diversificación de tipos de leyes en nada afecta a la concepción débil siempre y cuando los tipos de leyes reconocidos en un sistema dado cumplan los requisitos genéricos de estructura de las normas y se relacionen entre ellas conforme a criterios de competencia o jerarquía claros, públicos y prospectivos. Afecta, sin embargo, a la concepción fuerte (el imperio de la ley como expresión de la "voluntad general") en cuanto aparentemente quiebra la noción de que la ley es única y suprema. Deja de ser única porque hay diferentes tipos de leyes y deja de ser suprema en cuanto algunas de ellas son superiores a las otras (en la diversificación vertical) o todas ellas están por debajo de la norma que divide la competencia (en la diversificación horizontal). Pero esto sólo afecta a una noción de ley que tuvo predicamento ante una realidad jurídica - la del Estado liberal de Derecho en su forma continental- más simple que la actual. La suposición de que el concepto de ley y de su imperio implica un único tipo de ley era una constatación derivada de la estructura de los sistemas jurídicos modernos tras la consolidación del Estado-nación. Pero no hay, en la idea de ley como expresión de la "voluntad general", ninguna implicación necesaria de que la ley constituya un tipo único, o un grado jerárquico único. Lo que tienen en común diversos tipos de normas como la Constitución, las leyes orgánicas, las ordinarias, las autonómicas, las estatales o las federales, es su peculiar autor y su peculiar procedimiento de decisión, que exige una discusión abierta entre representantes de los electores (o entre ellos mismos, en el caso de un referéndum) y una decisión por mayoría. Es esta doble peculiaridad -el carácter directamente representativo y plural del órgano competente y el procedimiento deliberativo- lo que define a la ley como expresión de la "voluntad general" y, en este sentido, la pluralidad de manifestaciones de la "voluntad general" en nada afecta al carácter de la ley, a su legitimidad y a su pretensión moral de obediencia.

-(2) La aparición de normas no legales de carácter paralegal tampoco parece afectar en absoluto a la concepción débil. Las normas comunitarias, sean cuales sean las dificultades para dar cuenta del sistema de fuentes resultante en los sistemas jurídicos internos, parecen reunir los requisitos que la concepción débil exige de las normas. Sin embargo constituyen una quiebra total de la concepción fuerte. No se trata en este caso de que obliguen a cambiar o corregir algún elemento de nuestro concepto normativo de ley, se trata de que no lo satisfacen en absoluto. Y ello no parece ser un problema conceptual sino un urgente problema real. De modo que la concepción fuerte no deja alternativa: o reivindicamos la democratización de la Unión Europea o hacemos dejación de nuestra concepción moral del imperio de la ley. Lo único que cabe decir es que la realidad jurídica no corre, ni nunca ha corrido, pareja con su deseable 
legitimidad. El Derecho comunitario es, en este aspecto, necesariamente perfectible y, lo que es más grave, urgentemente perfectible. Su reconversión, su maduración, en términos de imperio de la ley no es sólo algo deseable, es algo necesario si quiere merecer nuestro respeto.

-(3) La supremacía de la Constitución, y su expansiva fuerza normativa, tampoco afecta a la concepción débil por las mismas razones indicadas en (1). Sí parece, sin embargo, poner en crisis aquellos otros tres rasgos tradicionalmente asociados a la concepción fuerte del imperio de la ley (su carácter originario, supremo e incondicional). Pero de nuevo habría que señalar que tales rasgos son contingentes para este concepto. El mismo Locke ([1690] 1969, Capítulo XI, \& 135) sostenía que el poder legislativo supremo, "a pesar de que sea el supremo poder de cualquier Estado", está sometido a restricciones pues no puede ser superior al poder que los miembros de la sociedad tenían en estado de naturaleza. En realidad los rasgos de originariedad, supremacía e incondicionalidad corresponden más a los intentos de explicar la posición de la ley en la estructura del sistema normativo que a la concepción moral (normativa) del imperio de la ley. En el terreno explicativo es obvio que tales rasgos - por otra parte discutidos y discutibles- se trasladan a la Constitución. La forma última en sentido jerárquico en que la voluntad general se expresa es la Constitución, y la Constitución es bien definida como primera instancia de poder legislativo. Es necesario, por otra parte, romper la ecuación entre ley (o constitución) y soberanía, porque el concepto de soberanía es una vaporosa imagen de una forma política periclitada. Lo que nos importa es que las leyes sean expresión de la voluntad general y, por ello, que en cada escalón de la constitución o desenvolvimiento de las comunidades políticas, las decisiones normativas estén originariamente legitimadas democráticamente. Una soberanía escalonada sigue siendo un ejercicio colectivo de la libertad negativa mediante las técnicas de instrumentación de la libertad positiva. Una Constitución es un momento del pacto social, pero un momento muy limitado, y el pacto social sólo puede ser una realidad actuante en la medida en que se actualiza mediante la legislación.

-(4) La fuerza expansiva de los principios, que actúa unida a la expansiva normatividad de las constituciones, sí parece plantear problemas a ambas concepciones del imperio de la ley. A la concepción débil en la medida en que, como se reconoce expresamente, supone una progresiva judicialización del Derecho y, con ello, un debilitamiento de la función de aplicar reglas en favor de "aplicar" razones. ${ }^{31}$ Más todavía quiebra los requerimientos de la

${ }^{31}$ Vid. J. C. Bayón 1996, p. 24: "el ideal clásico del imperio de la ley requiere un derecho de reglas, por cuanto un derecho de principios daría lugar a un modelo de jurisdicción sobre la 
concepción fuerte cuando sitúa al juez por encima de toda "perentoriedad normativa". Porque el juez, o cualquier otro funcionario a quien corresponda el rol de aplicar las normas de un sistema dado, no tiene otra legitimación que aquélla que tengan las normas (sean éstas normas-regla o normas-principio) de ese sistema. Su legitimidad no proviene de la representación, sino de la función. Pero la función, contra lo que Bachof dijo, no es ni ajena ni alternativa, ni mucho menos superior, al título. La única legitimidad del juez es la propia legitimidad del sistema del que es operador cualificado e, inevitablemente, en algún grado creador. Por lo tanto la única legitimidad del juez democrático es aplicar las leyes -y los principios- del sistema democrático. Y ello exige un "principio fuerte de deferencia" (Bayón 1996, p. 31) del juez ante la ley.

Posiblemente la legislación es hoy deficitaria, si es que alguna vez no lo ha sido, en calidad. Posiblemente el legislador democrático es un muy imperfecto espejo de una comunidad ideal de decisión racional. Pero el legislador democrático, y sus leyes, son hoy por hoy $-\mathrm{y}$ mientras no se demuestre lo contrario- no sólo el menos malo de los sistemas posibles de decisión colectiva sino, sin duda alguna, el mejor de todos los conocidos. Y cuando la ley es expresión de la voluntad popular su imperio constituye el primer imperativo de la moral colectiva.

Como al principio indiqué, la lectura de dos recientes e interesantes monografías sobre la crisis de la ley, ambas todavía inéditas, no me han hecho modificar estos puntos de vista. Si los he traído a colación, en forma resumida, es sólo para dejar claro que, entendida como la entiendo, la llamada "crisis de la ley" tiene mucho que ver con el problema de la soberanía, con la organización de los estados, con la fuerza normativa de las constituciones, con la fuerza normativa de los principios y con la función de los jueces, pero muy poco que ver, si es que tiene algo que ver, con el problema de la igualdad.

\section{Bibliografía citada}

Alexy, Robert (1993): Teoría de los derechos fundamentales, Centro de Estudios Constitucionales, Madrid. (Orig: Theorie der Grundrechte, Suhrkamp, Berlin, 1986)

AÑón, Ma José (1994): Necesidades y derechos: un ensayo de fundamentación, Centro de Estudios Constitucionales, Madrid

Aristóteles (1989): Política, edición de J. Marías y M. Araujo, Centro de Estudios Constitucionales, Madrid

AtienZa, Manuel (1983): Marx y los derechos humanos, Mezquita, Madrid

pauta de la «jurisprudencia de razones» que frustraría el propósito primario de servir de condición de posibilidad de la autonomía individual." 
BACHOF, Otto (1985): Jueces y Constitución, Civitas, Madrid (Orig: Grundgesetz und Richtermacht, J.C.B. Mohr-Paul Siebeck, Tubinga, 1959).

BARKer, Paul (2000): Vivir como iguales. Apología de la justicia social, Paidós, Barcelona (Orig: Living as Equals, Oxford University Press, Oxford, 1996).

BAYÓN, Juan C. (1996): Principios y reglas: legislación y jurisdicción en el Estado constitucional, inédito.

BobBio, Norberto (1991): Teoría General del Derecho, Debate, Madrid (Orig: Teoria della norma giuridica y Teoria dell' ordinamento giuridico, Giappichelli, Turín, 1958 y 1960).

- (1993) Igualdad y Libertad, Paidós/ICE-UAB, Barcelona. (Orig: EquaglianzaLibertá, voces en la Enciclopedia del Novecento, vol. II, pp. 355-364 y vol. III, pp. 994-1004, Istituto dell'Enciclopedia Italiana, Roma, 1977 y 1979).

Borges, Jorge L. (1993): Artificios, Alianza, Madrid.

Cranston, Maurice (1985): Rousseau on Equality, en Paul, Ellen F., Miller Jr., Fred D. y Paul, Jeffrey (eds.) 1985, pp. 115-124.

Doyal, Len y Gough, Ian (1994): Teoría de las necesidades humanas, Fuhem/Icaria, Madrid. (Orig: A Theory of Human Needs, The MacMillan Press, Londres, 1991).

Dworkin, Ronald (1984): Los derechos en serio, Ariel, Barcelona (Orig: Taking Rights Seriously, Gerald Duckworth, Londres, 1977).

ECKHOFF, Torstein (1974): Justice. Its Determinants in Social Interaction, Rotterdam University Press, Rotterdam.

Hernández Marín, Rafael (1989): Teoría general del Derecho y de la Ciencia jurídica, Promociones y poblicaciones universitarias, Barcelona.

Hierro, Liborio L. (1982): ¿Derechos humanos o necesidades humanas? Problemas de un concepto, Sistema $\mathrm{n}^{\circ} 46$, pp. 45-61.

- (1995) Las huellas de la desigualdad en la Constitución, en Mate, Reyes (ed.) 1995, pp. 131-150.

- (1996) El imperio de la ley y la crisis de la ley, DOXA nº 19, pp. 287-308.

- (1998) Estado de Derecho. Problemas actuales, Fontamara, México (2ª edición en 2001).

- (2002) Justicia, igualdad y eficiencia, Centro de Estudios Constitucionales, Madrid.

Kymlicka, Will (1995): Filosofia política contemporánea, Ariel, Barcelona (Orig: Contemporary Political Philosophy. An Introduction, Oxford University Press, Oxford, 1990; $2^{\mathrm{a}}$ edición en 2002).

LAPORTA, Francisco J. (1985): El principio de igualdad: introducción a su análisis, Sistema $\mathrm{n}^{\mathrm{o}} 67$, pp. 3-31

LockE, John [1690] (1969): Ensayo sobre el Gobierno Civil, Aguilar, Madrid.

Marcilla Córdoba, Gema Ma (2003): Crisis de la ley y Ciencia de la legislación, tesis doctoral, Universidad de Castilla-La Mancha (Albacete), inédita.

MARTíNEZ TAPIA, Ramón M. (2000): Igualdad y razonabilidad en la justicia constitucional española, Universidad de Almería, Almería

Mate, Reyes (ed.) (1995): Pensar la igualdad y la diferencia. Una reflexion filosofica, Fundación Argentaria/Visor, Madrid. 
Marx, Carlos [1891] (1968): Crítica del Programa de Gotha, Ricardo Aguilera editor, Madrid.

Nielsen, Kai (1985): Equality and Liberty, A Defense of Radical Egalitarianism, Rowman \& Allanheld, Totowa (N.J.).

Paul, Ellen F., Miller Jr., Fred D. y Paul, Jeffrey (eds.) (1985): Liberty and Equality, Basil Blackwell, Oxford.

Ross, Alf (1971): Lógica de las normas, Tecnos, Madrid (Orig: Directives and Nor$m s$, Routledge \& Kegan Paul, Londres, 1968).

Rousseau, Juan Jacobo [1762] (1969): Contrato social, Espasa Calpe, Madrid.

Ruiz Miguel, Alfonso (1994): Discriminación inversa e igualdad, en Valcárcel, Amelia (comp.) 1994, pp. 77-93.

- (1995) Las huellas de la igualdad en la Constitución, en Mate, Reyes (ed.) 1995, pp. 109-129.

- (2002a) La igualdad política, Derechos y Libertades no 11, pp. 65-98.

- (2002b) Concepto y concepciones de la igualdad, en Zapatero, Virgilio (ed.) 2002, pp. 671-700.

Singer, Peter (1984): Etica práctica. Ariel, Barcelona (Orig: Practical Ethics, Cambridge University Press, 1979).

SuÁRez, Miguel Angel (2003): Crisis de la ley y Estado constitucional, tesis doctoral (pendiente de lectura), Universidad Carlos III de Madrid, inédita.

Tomás y Valiente, Francisco (1979): Manual de Historia del Derecho español, Tecnos, Madrid.

Valcárcel, Amelia (comp.) (1994): El concepto de igualdad, Edit. Pablo Iglesias, Madrid.

Walzer, Michael (1993): Las esferas de la justicia, Fondo de Cultura Económica, México (Orig: Spheres of Justice. A Defense of Pluralism and Equality, Basic Books, 1983).

Westen, Peter (1990) Speaking of Equality. An Analysis of the Rethorical Force of "Equality" in Moral and Legal Discourse, Princeton University Press, Princeton (N.J.).

Wright, Georg H. von (1979): Norma y acción. Una investigación lógica, Tecnos, Madrid (Orig: Norm and Action. A Logical Enquiry, Routledge \& Kegan Paul, Londres, 1963).

Young, Michael (1964) El triunfo de la meritocracia. Un ensayo sobre la educación $y$ la igualdad, Tecnos, Madrid (Orig: The Rise of the Meritocracy, Thames and Hudson, Londres, 1958).

Zapatero, Virgilio (ed.) (2002): Horizontes de la Filosofía del Derecho. Homenaje a Luis García San Miguel, tomo 1, Universidad de Alcalá. 